\title{
DINÂMICA DAS VARIÁVEIS CLIMÁTICAS (TEMPERATURA DO AR, PRECIPITAÇÃO PLUVIOMÉTRICA E EVAPOTRANSPIRAÇÃO POTENCIAL) EM RELAÇÃO AOS FATORES GEOGRÁFICOS DO CLIMA NAS SUB-BACIAS HIDROGRÁFICAS DOS RIOS PIRANHAS E CAPIVARI (BACIA DO PARAGUAÇÚ - BA) COMO INDICADORES DO PROCESSO DE DESERTIFICAÇÃO
}

\author{
Thayane dos Santos Sales ${ }^{1}$; Elane Fiuza Borges ${ }^{2}$ \\ 1. Bolsista PROBIC/UEFS, Graduando em Bacharelado em Geografia, Universidade Estadual de Feira de Santana, e-mail: \\ thayane.sales19@gmail.com \\ 2. Orientador, Departamento de Ciências Humanas e Filosofia, Universidade Estadual de Feira de Santana, e-mail: \\ elaneborges@gmail.com
}

PALAVRAS-CHAVE: Dinâmica Climática; Bacia hidrográfica; Superfície terrestre.

\section{INTRODUÇÃO}

A diversidade de fisionomias dos ambientes naturais existentes na superfície terrestre é fruto de uma complexidade de forças antagônicas que atuam internamente e externamente na configuração e reconfiguração das formas de relevo. O entendimento desses mecanismos nos fornece respostas às diversas configurações da paisagem e como esses processos são diferenciados em cada um dos planos: O biótico (animais e vegetais) e o abiótico (terra, água e ar). Essas dinâmicas foram contempladas neste estudo, porém tendo o clima como percussor principal na análise dos processos atuantes sobre as paisagens das sub-bacias hidrográficas do Rio Piranhas e Capivari situadas na bacia hidrográfica do Rio Paraguaçu - BA, sendo este esta analise um auxiliador nos estudos sobre os processos de degradação do solo em ambientes áridos, semi-áridos e sub-úmidos do Estado da Bahia, projeto ao qual este trabalho vinculou-se. Assim, em meio a essa problemática de cunho natural e social, é imprescindível que a ciência geográfica emprenhe-se no estudo singular das relações sociedade-natureza, buscando a partir do componente climático, iniciar uma análise geográfica que subsidie na compreensão da gênese e processos de natureza atmosférica intervenientes no espaço antropizado das sub-bacias supracitadas contribuindo nos estudos sobre a problemática da desertificação e na construção de planejamentos regionais mais eficazes. O estudo tratar-se de uma discussão calcada em fenômenos complexos que envolvem a dinâmica física-natural dos elementos climáticos e sua relação com os fatores geográficos existentes na região.

\section{MATERIAL E MÉTODOS}

O cerne das referências teóricas adotadas para a fundamentação da pesquisa abrange desde os clássicos concernentes à climatologia geral e sistemática, apresentados por Nimer (1989), Molion \& Bernardo (2000), Kayano \& Andreoli (2009) e (Christopherson, 2012) dentre outros para compreensão e apropriação teórica sobre os fenômenos em análise. As publicações de instituições estatais de pesquisa como CEPLAB (1978), CEI (1991) e SEI (1998) e sobre a distribuição e caracterização climática do Estado da Bahia. Sendo, todas as obras supracitadas anteriormente, articuladas as discussões sobre o Processo de desertificação, tendo as publicações de Matallo Jr (2001), PAN-Brasil (2004), Conti (2008), Souza (2008) adotadas e articuladas ao processo de Degradação Ambiental no Estado da Bahia, tema do projeto de pesquisa a qual o plano de pesquisa se adequou. As áreas selecionadas para estudo são as Sub-bacias Hidrográficas do Rio Capivari e a do Rio Piranhas. A primeira considerada o principal afluente da Bacia Hidrográfica do Baixo Paraguaçu, destacando-se como uma das principais unidades de beneficiamento das atividades agropastoris na região e para o abastecimento de municípios situados na Bacia Hidrográfica do Baixo Médio Paraguaçu, porção onde está situado o município de São Félix, onde fica a região de sua foz 
(Dourado, 2010). A segunda sub-bacia hidrográfica está situada à margem esquerda do Rio Paraguaçu, em seu setor médio, no centro-leste da Bahia, compreende as coordenadas: $12^{\circ} 25^{\text {' }}$ $48^{\prime \prime}$ e $12^{\circ} 33^{\prime} 42$ de latitude sul e $40^{\circ} 38^{\prime} 31^{\prime}$ ' e $40^{\circ} 1^{\prime} 19$ de longitude a oeste, abrangendo os municípios de Itaberaba, Boa Vista do Tupim e Ruy Barbosa, sendo esta a região de maior produção de abacaxi pérola para exportação no Estado da Bahia.

Para que fosse possível dar início aos estudos foi imprescindível à estruturação de um banco de dados e também, a seleção de alguns softwares e ferramentas computacionais, úteis na execução do trabalho. Os dados coletados foram exportados para ambiente SIG (Sistema de Informações Geográficas), onde a área de estudo inicialmente foi delimitada. Para a delimitação das sub-bacias foi utilizado um MDE derivado da imagem SRTM com resolução de 90 x 90, obtida pelo projeto Topodata (www.dsr.inpe.br/topodata). Após a aquisição das cenas, as mesmas foram processadas utilizando o programa ARCGIS VERSÃO 10.0 no qual foi realizado inicialmente um mosaico, obtendo assim um único arquivo, com a combinação das quatro imagens. A segunda fase da pesquisa foi espacializar os dados climáticos outrora citados, para tal utilizou-se o interpolador Krigagem. Este interpolador é considerado uma boa metodologia de interpolação de dados, contudo só apresenta bons resultados quando o espaço amostral é considerável, ou seja, é preciso ter uma boa quantidade dados, neste caso, estações meteorológicas, distribuídas no espaço em análise para que a metodologia traga resultados satisfatórios. O espaço amostral utilizado foi disponibilizado pelo Balanço Hídrico da SEI (1999), a qual se obteve 58 pontos amostrais, sendo este uma boa amostra em relação às unidades das bacias adotadas para estudo.

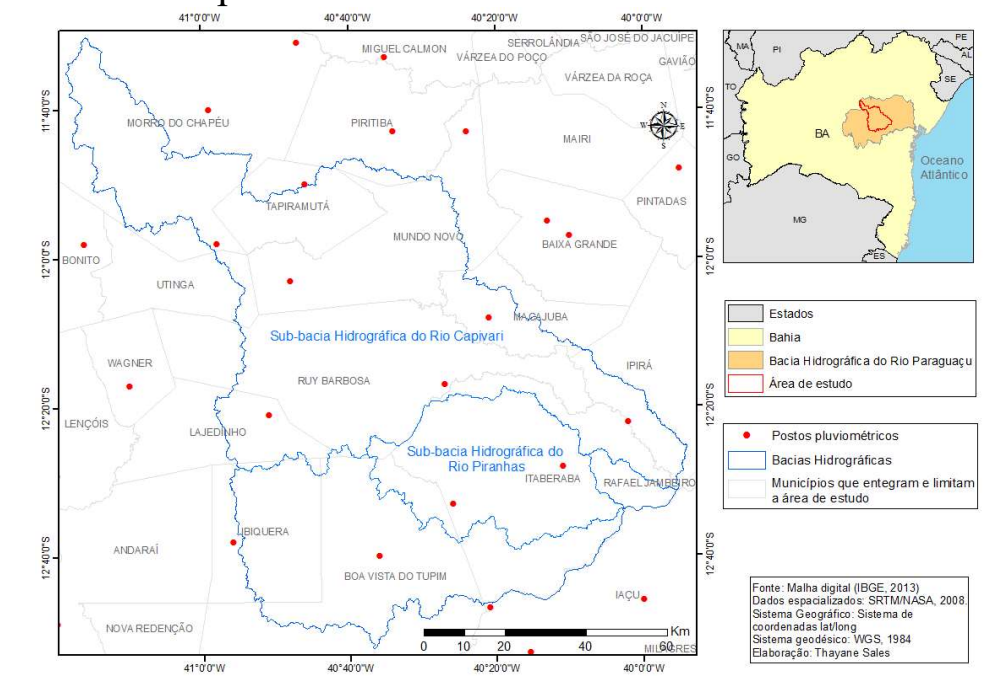

Figura 1 - Mapa de localização das áreas de Estudo

\section{RESULTADOS E DISCUSSÕES}

As duas sub-bacias foram estudadas de forma correlata em vista de ambas situarem em um mesmo ambiente climático (Tropical Semi-árido) como em alguns momentos de análise, dissociadas em função de alguns fatores geográficos apresentarem comportamentos físicos interativos diferenciados em cada uma dos ambientes naturais. As sub-bacias hidrográficas em questão apresentam temperaturas (E) com mínimas de $21,4^{\circ} \mathrm{C}$ a noroeste e com máximas de $24,8^{\circ} \mathrm{C}$ à sudeste. As áreas onde as temperaturas mínimas predominam (entre $21,4^{\circ} \mathrm{a}$ $23,5^{\circ} \mathrm{C}$ ) compreendem a montante da sub-bacia hidrográfica do Rio Capivari, onde estão situados os municípios de Tapiramutá e Morro do Chapéu. Em relação às temperaturas máximas, as mesmas caracterizam a leste e jusante da sub-bacia hidrográfica do Rio Piranhas e Rio Capivari, com temperatura média em torno de $24,5^{\circ} \mathrm{C}$ compreendendo os municípios de Itaberaba e Rafael Jambeiro. Um dos principais fatores geográficos de influência na organização térmica e pluviométrica das áreas de estudo é a altitude dos distintos conjuntos geomorfológicos que compreendem as sub-bacias. Segundo os mapas de hipsometria e 
declividade (A) e (C), a topografia em especial da sub-bacia do Rio Capivari apresenta-se desde regiões de relevo movimentado, como as Encostas Ocidentais da Chapada Diamantina e Patamares do alto/médio Capivari (1), até áreas planas de topografia monótona como o Pediplano Sertanejo (2) da bacia hidrográfica do Rio Piranhas e Baixo curso do Rio Capivari, envolvidos por relevos colinosos, residuais dissecados e de planícies aluvionares (D). Tratando-se da distribuição pluviométrica no setor (1) da área de estudo, o mesmo apresenta uma associação dos sistemas atmosféricos em conjunto com o relevo, o que resulta em uma distribuição pluviométrica (G) média anual variando de $630 \mathrm{~mm}$ a noroeste, a $961 \mathrm{~mm}$ a sudeste da área de estudo. É possível verificar que o efeito do relevo potencializa o acréscimo de precipitação média anual, indicando singularidades no que diz respeito à variabilidade espacial da chuva. Neste ambiente a pluviometria, a estrutura geomorfológica (D) e a vegetação (B) apresentam-se bastante dependentes, principalmente quando analisamos a fragilidade potencial do relevo, a declividade elevada e a inexistência de vegetação com o avanço das atividades agropastoris, o que torna os processos de transporte de materiais mais intensos, impulsionados pela ação gravitacional. Assim, os processos erosivos se processam de forma mais rápida no ambiente, em vista do aumento do desmatamento, da falta de um manejo adequado nas atividades agrícolas "atuais" e dos desequilíbrios outrora provocados pelas antigas atividades de mineração que ocorreram na região. A evapotranspiração potencial (H) está condicionada tanto ao fator térmico como ao fator hídrico e os tipos de solos da região. As altas taxas de evaporação que ocorrem neste setor, em torno de 1200 a $1260 \mathrm{~mm}$, tanto em superfícies livres de água (açudes, represas, etc.) como no solo, representando uma perda significativa na disponibilidade hídrica no ambiente.

A unidade do Pediplano Sertanejo (2) possui uma grande representatividade na área em estudo, predominando com grande extensão em toda a porção centro leste da bacia do rio Piranhas e a montante do Rio Capivari. Essas áreas correspondem a uma superfície deprimida, com altitudes que variam entre 200 e 600 metros (A), cercada em parte por relevos planálticos de unidades adjacentes. As formas de relevo mais comuns e notáveis nesta unidade são os "dorsos de baleia" e os inselbergs. Neste ambiente, os totais pluviométricos (G) deste setor compreendem de $720 \mathrm{~mm}$ a $780 \mathrm{~mm}$, apresentando um regime de chuvas marcado por períodos de escassez, em especial na porção sul deste setor.

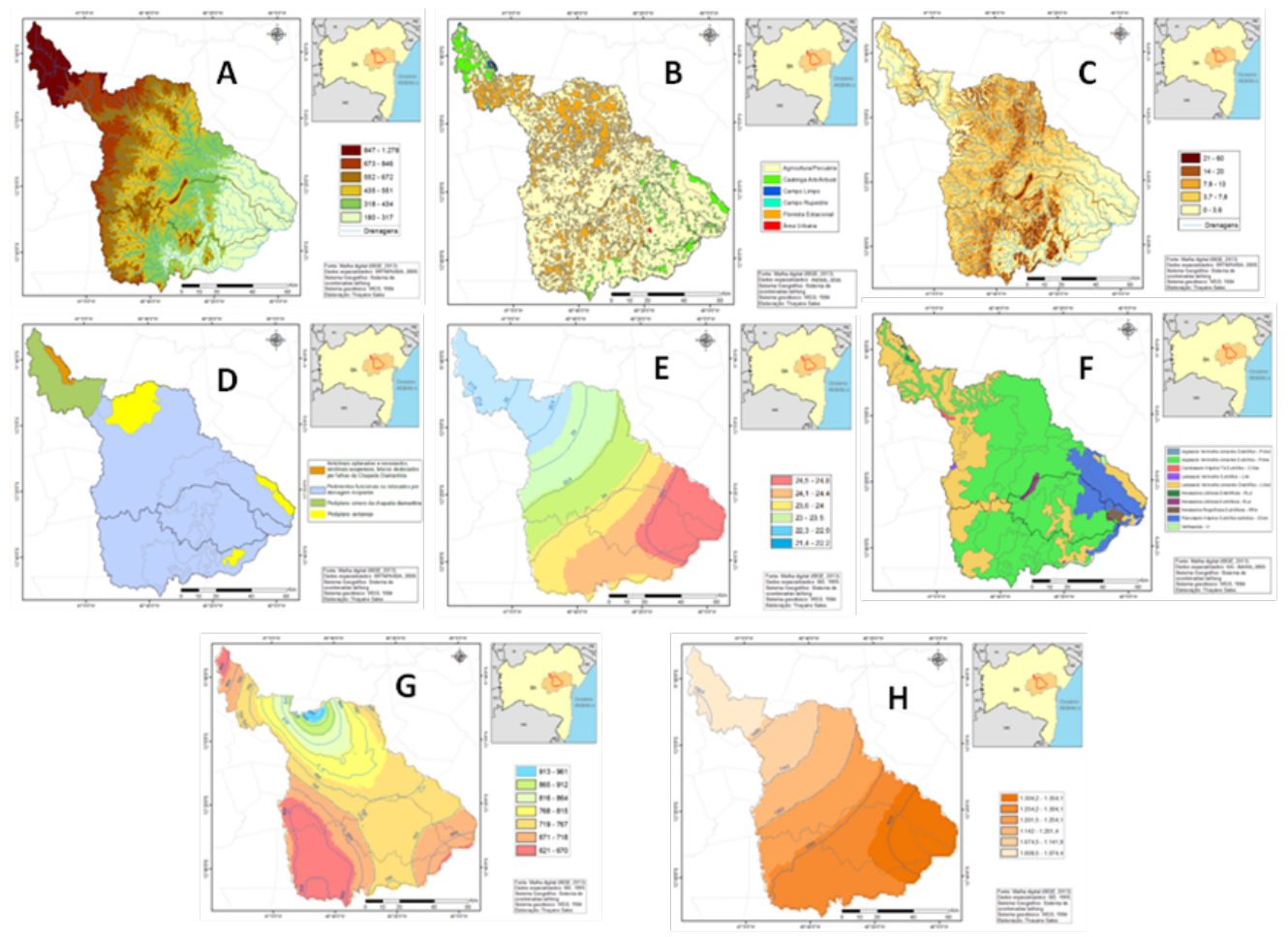

Figura 2. A) Mapa de altimetria, B) Uso e ocupaçäo do solo, C) Declividade, D) Geomorfologia, E) Temperatura do ar, F) Pedologia, G) Precipitação pluviométrica e H) Evapotranspiraçäo potencial. 
Nesta região há uma acentuada irregularidade espaço-temporal das chuvas e longos períodos de estiagem, onde a maior parte da precipitação, geralmente, ocorre em três meses, compreendendo o período do verão e outono. Neste setor da área de estudo, o bioma caatinga em função do clima tropical semi-árido é a vegetação predominante, contudo, é uma caatinga antropizada, onde grande parte da vegetação já foi suprimida pela permanente exploração ao longo dos anos em todo o processo de colonização das terras, sendo as atividades de pecuária primeiramente e agrícola as principais intervenções. Essas alterações na paisagem da subbacia são provocadas por práticas inadequadas de ocupação e uso do solo ao longo de dezenas de anos. Neste ambiente houve alteração da dinâmica natural e frágil do ecossistema regional (caatinga), causando grandes desequilíbrios. Os principais impactos ambientais neste setor são atribuídos às atividades agropecuárias e extrativismo vegetal, bem como desmatamento e utilização de agrotóxicos a disposição inadequada de resíduos sólidos e o desmatamento (INGÁ, 2008).

\section{CONCLUSÕES}

A realização do presente estudo utilizando-se do método sistêmico, bem como de uma série de procedimentos metodológicos concebidos em diversos campos do conhecimento geográfico e, portanto científico, que permitiu a verificação das diferentes correlações entre os fatores geográficos e os elementos climáticos mais significativos para analise e como estes respondem as atividades produtivas no espaço. Em geral, concluo que são as formas de uso e ocupação que determinam para que lado pesa a balança estabilidade/vulnerabilidade ambiental das sub-bacias hidrográficas do Rio Capivari e Rio Piranhas, pois cada unidade possuem sua própria dinâmica natural e deve ser conservada, ou seja, não sobrepondo a capacidade regenerativa de cada ambiente. Das degradações observadas, a mais preponderante foi o desmatamento da caatinga na maior parte da área de estudo, intervenção essa que contribui para acelerar a ação das gotas de chuva sobre o solo exposto (efeito splash) em razão da ausência de uma camada protetora (cobertura vegetal). Assim, o escoamento superficial passar a ser potencializado, provocando o aparecimento de pequenas ravinas, as quais poderão evoluir para sulcos e, até mesmo, para voçorocas, dependendo da declividade do terreno, no caso do alto e médio Capivari e da intensidade e frequência das precipitações, sendo estas concentradas em um curto período de tempo-espaço.

\section{REFERÊNCIAS}

KAYANO, M. T; ANDREOLI, R. V. Clima da região Nordeste do Brasil. In: CAVAlCANTI, I. F. de A. et. al.(Org.). Tempo e clima no Brasil. São Paulo: Oficina de Textos, 2009. cap. 14, p. 213-233.

MATALLO JUNIOR, H. Indicadores de desertificação: histórico e perspectiva. Brasília, DF: UNESCO, 2001.

MINISTÉRIO DO MEIO AMBIENTE. Secretaria de recursos hídricos. Programa de ação nacional de combate à desertificação e Mitigação dos efeitos da seca Pan-Brasil, 2004.

MOLION, L. C. B., BERNARDO, S. O: Dinâmica das Chuvas no Nordeste Brasileiro. XI Congresso Brasileiro de Meteorologia, 2000.

NIMER, E. Climatologia do Brasil. Departamento de recursos naturais e estudos ambientais. Instituto Brasileiro de Geografia e Estatística, Rio de Janeiro, $2^{\mathrm{a}}$ edição, 1989.

Superintendência de Estudos Econômicos e Sociais da Bahia - SEI. Balanço hídrico do estado da Bahia. (Série Estudos e Pesquisas, 45). Salvador: SEI, 1999.250 p. 